\title{
ESPECULACIÓN URBANÍSTICA Y BURBUJA INMOBILIARIA EN ESPACIOS LITORALES: FACTORES EXPLICATIVOS DEL TERCER BOOM TURÍSTICO DE CANARIAS ${ }^{1}$
}

\author{
Moisés Simancas Cruz. \\ Universidad de La Laguna
}

\section{RESUMEN}

La dinámica del turismo en las Islas Canarias (España) se ha desarrollado en ciclos económicos. Ello implica la sucesión de momentos de expansión y contracción, que podemos denominar booms turísticos. El tercero (1997-2001) se caracterizó por unas extraordinarias expectativas empresariales, reales y potenciales, de construcción de nuevos alojamientos turísticos. Sin embargo, éstas no respondieron a una demanda real, sino a procesos de especulación urbanística derivadas de los incentivos públicos a la inversión, así como al predominio de los principios de desregulación, privatización y liberalización del mercado. El principal objetivo de este trabajo es analizar los factores urbanísticos-especulativos que explican la génesis y el desarrollo de este tercer boom turístico canario.

Palabras clave: área turística de litoral, especulación urbanística, burbuja inmobiliaria.

Fecha de recepción: 11 de diciembre de 2017

Fecha de aceptación: 22 de mayo de 2018

Departamento de Geografía e Historia. Universidad de La Laguna. C/ Prof. José Luis Moreno Becerra, s/n. Facultad de Humanidades. Sección de Geografía e Historia. Planta 2. Apartado 456. 38200 San Cristóbal de La Laguna. Santa Cruz de Tenerife (España). E-mail: msimancas@ull.es Grupo de investigación ReinvenTUR: Observatorio de la Renovación Turística. Universidad de La Laguna. Cátedra de Turismo CajaCanarias-Ashotel de la Universidad de La Laguna.

$1 \mathrm{La}$ investigación que da lugar a este trabajo constituye uno de los resultados del proyecto "Análisis de la sostenibilidad urbana como estrategia de regeneración del espacio público de las áreas turísticas de litoral”, financiado por la Fundación CajaCanarias y gestionado por el Vicerrectorado de Investigación de la Universidad de La Laguna. Asimismo, se inscribe en el proyecto titulado "Crisis y reestructuración de los espacios turísticos del litoral español” (CSO2015-64468-P) del Ministerio de Economía y Competitividad (MINECO). 


\title{
Urbanistic speculation and real estate bubble in the coastal space: explanatory factors
} of the third tourism boom of the Canary Islands

\begin{abstract}
The dynamics of tourism in the Canary Islands (Spain) has developed following economic cycles, with the reality succession of times of expansion and contraction, which can be called tourism booms. The third (1997-2001) are characterized by extraordinary business expectations, real and potential, to build new tourist accommodations. However, the processes of urban speculation derived from public incentives for investment and the predominance of the principles of deregulation, privatization and market liberalization. The main objective of this paper is to analyse the urbanistic-speculative factors that explain the genesis and development of the third canarian tourist boom.
\end{abstract}

Keywords: coastal tourism, urbanistic speculation, housing bubble.

\section{INTRODUCCIÓN}

El desarrollo territorial del turismo en las Islas Canarias (España) se ha caracterizado por la combinación de períodos de aceleraciones o de crecimiento rápido (superior a la tendencia), que se alternan con otros de desaceleraciones, crecimiento lento, estancamiento o recesión (inferior a la tendencia). Por tanto, presenta momentos de crecimiento explosivo o momentos de expansión (auges), en horizontes temporales de mediano plazo, que podemos calificar como booms turísticos. Estos han sido definidos y descritos, entre otros, por Martín-Ruiz (2001), Hernández y Rodríguez (2007), Macías y Rivero (2009), Hernández (2010) y García Cruz (2014).

Tras una fase recesiva entre 1993 y 1995, en la que disminuyó el número de turistas, debido, entre otras razones, a la crisis internacional, entre 1996 y 2001 se produjo una etapa de expansión que hemos denominado como "tercer boom turístico canario". Supuso un momento de "desarrollo fácil del turismo" (Hernández, 2010), como consecuencia de un importante dinamismo del binomio "turismo-construcción", derivado de las extraordinarias expectativas empresariales, reales y potenciales, consecuencia de la existencia de los incentivos públicos a la inversión y del predominio de los principios de desregulación, privatización y liberalización del mercado. De esta manera, el tercer boom turístico canario se insertó en el proceso español de especulación urbanística y de burbuja inmobiliaria descrito, entre otros, por Artigues y Rullán (2007), Burriel (2008 y 2014), Ocaña (2009), Rullán (1999 y 2012), Blázquez y Murray (2010), Naredo (2010), Romero (2010), Rodríguez y López (2001), Mata (2011), Romero, Jiménez y Villoria (2012) y Lois et al. (2016); sus efectos en forma de urbanismo expansivo sobre el litoral turístico han sido analizados, entre otros, por Vera (1990), Díaz y Lourés (2008), Rullán (2008 y 2011), Gaja (2008), Santos y Fernández (2010), Martí y Nolasco (2011), Pulido (2011), Obiol y Pitarch (2011), García Cruz (2014) y Membrado, Huete y Mantecón (2016). Ello generó unos registros de valores críticos en relación con los principales indicadores del 
negocio turístico, y, sobre todo, un riesgo de desfase entre la oferta de alojamiento y la demanda, emitiendo "señales de alerta", que dieron lugar a la intervención en 2001 del Gobierno de Canarias en forma de moratoria turística.

Este trabajo parte de la premisa de que el análisis de las etapas de crecimiento turístico contiene los elementos explicativos no solo de la propia expansión, sino del declive posterior (Hernández, 2010). Así, su objetivo principal es analizar los factores urbanísticos-especulativos que explican la génesis y el desarrollo del tercer boom turístico canario. Por ello hemos asumido la metodología de estudio de caso interpretativo o explicativo; al mismo tiempo, se ha optado por el enfoque de análisis de contenido o de correlato, de modo que el sujeto de observación de la investigación ha sido el propio proceso expansivo.

\section{CARACTERIZACIÓN DEL TERCER BOOM TURÍSTICO DE CANARIAS: LA GENERACIÓN DE UN ESCENARIO DE EXTRAORDINARIAS EXPECTATI- VAS DE CRECIMIENTO DE LA OFERTA DE ALOJAMIENTO TURÍSTICO}

El tercer boom turístico se inició con un significativo incremento de la afluencia turística (extranjeros y nacionales) anual, sobre todo, entre los años 1996 y 1997, del 15,6\% y $10,8 \%$, respectivamente. Según los datos del Instituto Canario de Estadística (ISTAC), ésta aumentó en 1.957.679 entre 1997 y 2001, año en el que se registraron 11.645.366 turistas, de los que el $87 \%$ fueron extranjeros. Asociado a este crecimiento de la demanda, la evolución del Indicador Sintético de la Actividad Turística elaborado por el ISTAC, que recoge información sobre la afluencia de turistas, el gasto por persona/día y la estancia media, experimentó un crecimiento espectacular del 37,1\% entre 1996 y 2001, siendo especialmente relevante en las islas de Fuerteventura $(54,1 \%)$ y Lanzarote $(48,1 \%)$. Ello fue consecuencia del mantenimiento del índice de ocupación hotelera durante el período 1995-1999 en torno al 80\%, lo que da cuenta de un aumento y mejora en la capacidad de este tipo de alojamiento turístico, en la medida que es dependiente de la misma. Asimismo, aunque la estancia media descendió de 9,21 a 8,65 días entre 1994 y 1998, se produjo un incremento en torno a un $11 \%$ en el número de pernoctaciones hoteleras, lo que da cuenta como el aumento de la capacidad hotelera; así, dicha disminución de la estancia media fue cubierta por la demanda. Del mismo modo, según estimaciones realizadas por Hernández (2004), durante el periodo 1996-1998, el crecimiento del sector turístico aportó cada año aproximadamente 2,7 puntos del crecimiento económico registrado en el bienio, que alcanzó la tasa de global de 4,8\%, siendo igualmente destacada la aportación en 1999.

Si bien esta coyuntura turística favorable no generó un crecimiento real de la oferta reglada de alojamiento turístico tan extraordinario como el del segundo boom turístico (1987-1993), estimado en un 34,6\%, la tasa de incremento de plazas de alojamiento turístico entre 1995 y 2000 fue del 9,3\% (gráfico 1). Así, el número de plazas regladas hoteleras (hoteles y hoteles apartamentos) y extrahoteleras (apartamentos, bungalows y villas) ascendió a 354.435 a fecha de 31 de diciembre de 2000, de las que 99.595 (el $28,1 \%$ ) se construyeron en los últimos seis años; ello supuso un "rejuvenecimiento" de la oferta de alojamiento a través de la incorporación de nuevas plazas en detrimento de su renovación. Este incremento hizo que Canarias se posicionara como la primera y segunda 
Comunidad Autónoma de "sol y playa" en cuanto al número de establecimientos turísticos de alojamiento y plazas turísticas, respectivamente.

\section{Gráfico 1}

\section{EVOLUCIÓN TEMPORAL DE LA ANTIGÜEDAD DE LA OFERTA DE ALO- JAMIENTO TURÍSTICO DE CANARIAS}

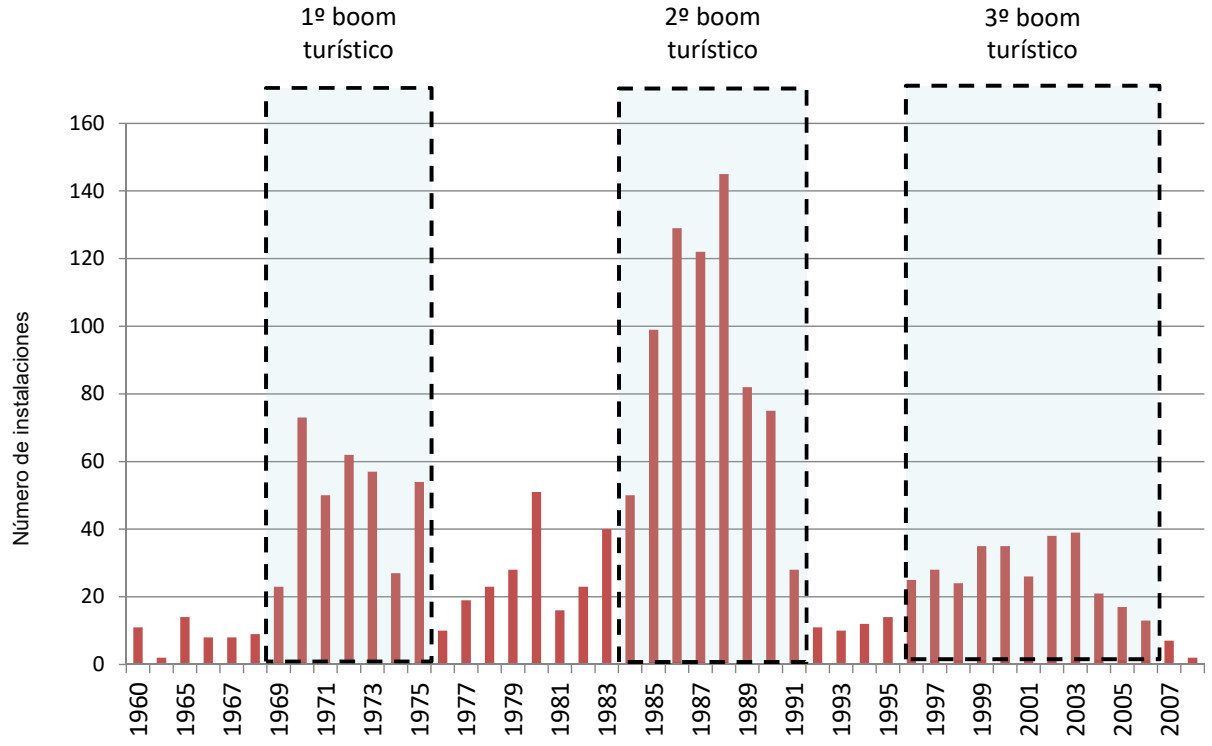

Fuente: Catastro de Urbana / Proyecto ReinvenTUR (2012) / García Cruz (2014). Elaboración propia.

El 95,9\% de la oferta de alojamiento turístico existente en Canarias en 2000 se concentró en cuatro de las siete islas del Archipiélago, las que hemos denominado como "turísticamente consolidadas": Tenerife, Gran Canaria, Fuerteventura y Lanzarote. Sin embargo, este crecimiento de la capacidad alojativa del Archipiélago presentó importantes contrastes entre dos grupos de islas: mientras para las citadas islas fue relativamente baja, pues, a excepción de Fuerteventura $(33,4 \%)$, la tasa fue negativa en Tenerife $(-0,3 \%)$ y se situó por debajo de la media $(23,1 \%)$ en Gran Canaria $(12 \%)$ y Lanzarote $(7,4 \%)$, para las "no consolidadas" o denominadas "islas verdes" fue alta, con tasas del 40,8\%, $40,5 \%$ y $28 \%$ en La Palma, El Hierro y La Gomera, respectivamente. De esta manera, esta etapa expansiva posibilitó la incorporación de este último grupo de islas al proceso de desarrollo turístico de litoral "de masas", así como que el mayor crecimiento de la oferta de alojamiento turístico se produjo en las islas con menor número de plazas hasta ese momento (gráfico 2). 


\section{Gráfico 2 \\ EVOLUCIÓN INSULAR DEL NÚMERO DE PLAZAS DE ALOJAMIENTO TURÍSTICA}

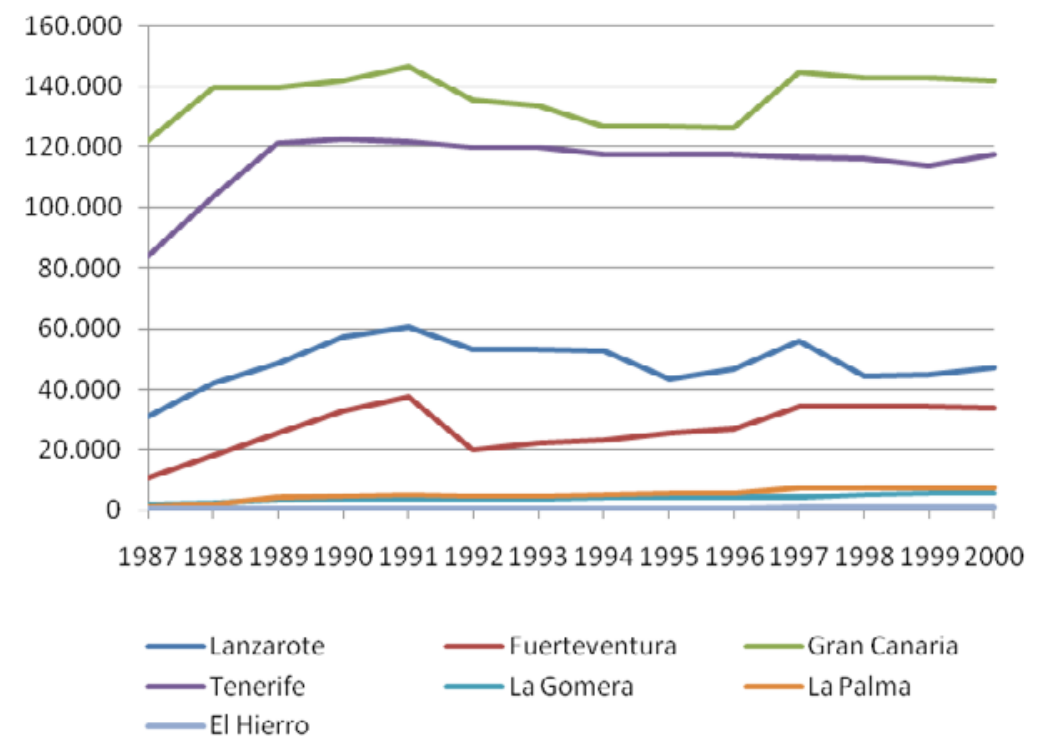

Fuente: ISTAC.

Sin embargo, el rasgo esencial del tercer boom turístico fue la generación de unas extraordinarias expectativas de crecimiento de la oferta de alojamiento turístico susceptibles de concretarse en un plazo corto (cuando las plazas en trámite de apertura se incorporasen al mercado), medio (las plazas con autorización previa en trámite) y largo (las plazas sin ejecutar por hallarse en suelo sin desarrollar, aunque previstas en el planeamiento como apto para su desarrollo turístico). Estas expectativas fueron consecuencia del importante volumen de autorizaciones turísticas previas concedidas por la Consejería de Turismo y Trasportes del Gobierno de Canarias, y a partir de agosto de 2000, por los Cabildos Insulares en virtud de la Ley 2/2000, de 17 de julio, de medidas económicas en materia de organización administrativa y gestión relativas al personal de la Comunidad Autónoma de Canarias y de establecimiento de normas tributarias.

En la medida en que verifica y determina la compatibilidad del destino turístico de un establecimiento de alojamiento turístico con la ordenación territorial turística y la normativa sectorial aplicable, la transcendencia de este tipo de autorización administrativa de naturaleza reglada prevista en la Ley 7/1995, de 6 de abril, de Ordenación del Turismo de Canarias, modificada por la Ley 7/1997, de 4 de julio, de Ordenación del Turismo de Canarias, actualmente derogada, por la Ley 5/1999, de 15 de marzo, radica en que constituye uno de los deberes fundamentales que se impone a los empresarios turísticos para el ejercicio de sus actividades (artículos 13.2.b y 21 de la Ley 7/1995). Su obtención opera 
como un auténtico requisito de validez - y no sólo de eficacia - de las licencias de cualquier tipo (de obras, de apertura, etc.), a concederse en suelo calificado como turístico, sancionándose con la nulidad de pleno derecho todas las que fueren concedidas sin disponer previamente de la misma (artículo 61 de la Ley 7/1995). Su ausencia determina la nulidad de la licencia de obras en virtud del artículo 170.5 del Decreto Legislativo 1/2000, de 8 de mayo, por el que se aprueba el Texto Refundido de las Leyes 9/1999, de Ordenación del Territorio de Canarias, y 12/1994, de Espacios Naturales de Canarias, lo cual explica el calificativo de "previa", en cuanto su otorgamiento resulta un requisito anterior e ineludible para su obtención. Los expedientes de tales autorizaciones se comprendieron con cinco tipos proyectos (Simancas, 2015): a) los de ciclo reciente pendientes de construirse $\mathrm{y}$, por tanto, susceptibles de incorporarse al mercado turístico en cualquier momento; b) los que ya estaban en el mercado, en su mayoría, de modo irregular, por no haber obtenido las autorizaciones definitivas por incumplimiento de los estándares turísticos de la Ley 7/1995, de 6 de abril, de Ordenación del Turismo de Canarias, modificada por la Ley 7/1997, de 4 de julio, de Ordenación del Turismo de Canarias, actualmente derogada, por la Ley 5/1999, de 15 de marzo y que buscaron su legalización ante la "alarma" del anuncio de una posible moratoria turística; c) los que contaban con licencia de obras "antigua", que no se ejecutaron por diversas razones, y que tenían que adaptarse y cumplir con la citada norma; d) los correspondientes a nuevas inversiones, que se encontraban a la expectativa de obtener licencia aunque fuese de forma irregular; y e) los que disponían de licencias de obras otorgadas por los ayuntamientos durante estos tres años.

Considerando que desde la decisión de un promotor de iniciar el procedimiento administrativo de solicitud de la autorización previa hasta su apertura definitiva pasa entre 30-36 meses (Díaz, Martín y Laiz, 2001) y 3-4 años (Exceltur, 2003), esas plazas de alojamiento turístico podían incorporarse al mercado, al menos, en el plazo de dos años, sumándose, por tanto, a la oferta de alojamiento turístico existente en el año 2000. Un informe interno de la Consejería de Turismo y Transportes del Gobierno de Canarias (2000), denominado "La incidencia de la expansión turística en la capacidad de carga de los sistemas insulares: necesidad de arbitrar medidas de contención del crecimiento desbordado", planteó que la oferta de alojamientos turísticos ascendía a 450.892 (escenario B de la tabla 1), al considerar las plazas que contaban con autorización de apertura en trámite y previa en trámite (con autorización del proyecto de construcción). Otro informe de la Consejería de Política Territorial y Medio Ambiente del Gobierno de Canarias (2001) situó ese techo en 596.368 plazas para los siguientes tres años y en un alarmante 1.109.720 al agregar las consideradas en el suelo calificado como turístico en los planes urbanísticos, generales y parciales, presentados ante las Administraciones Públicas competentes (escenario $\mathrm{C}$ de la tabla 1). Con posterioridad, la estimación del potencial turístico contenida en el documento de Avance de las Directrices de Ordenación del Turismo (2001) lo elevó a 1.332.878 plazas (escenario D de la tabla 1), al añadir las plazas que en ese momento estaban en funcionamiento o saldrían al mercado en un plazo no superior a tres años (596.368) al total de plazas expectantes (736.510); resulta llamativo que "se trataba de una previsión conservadora, dado que no se computan las plazas que se podría materializar en el suelo urbano en vías de consolidación y en el urbanizable en ejecución" (Baute y de Souza, 2001: 38). 


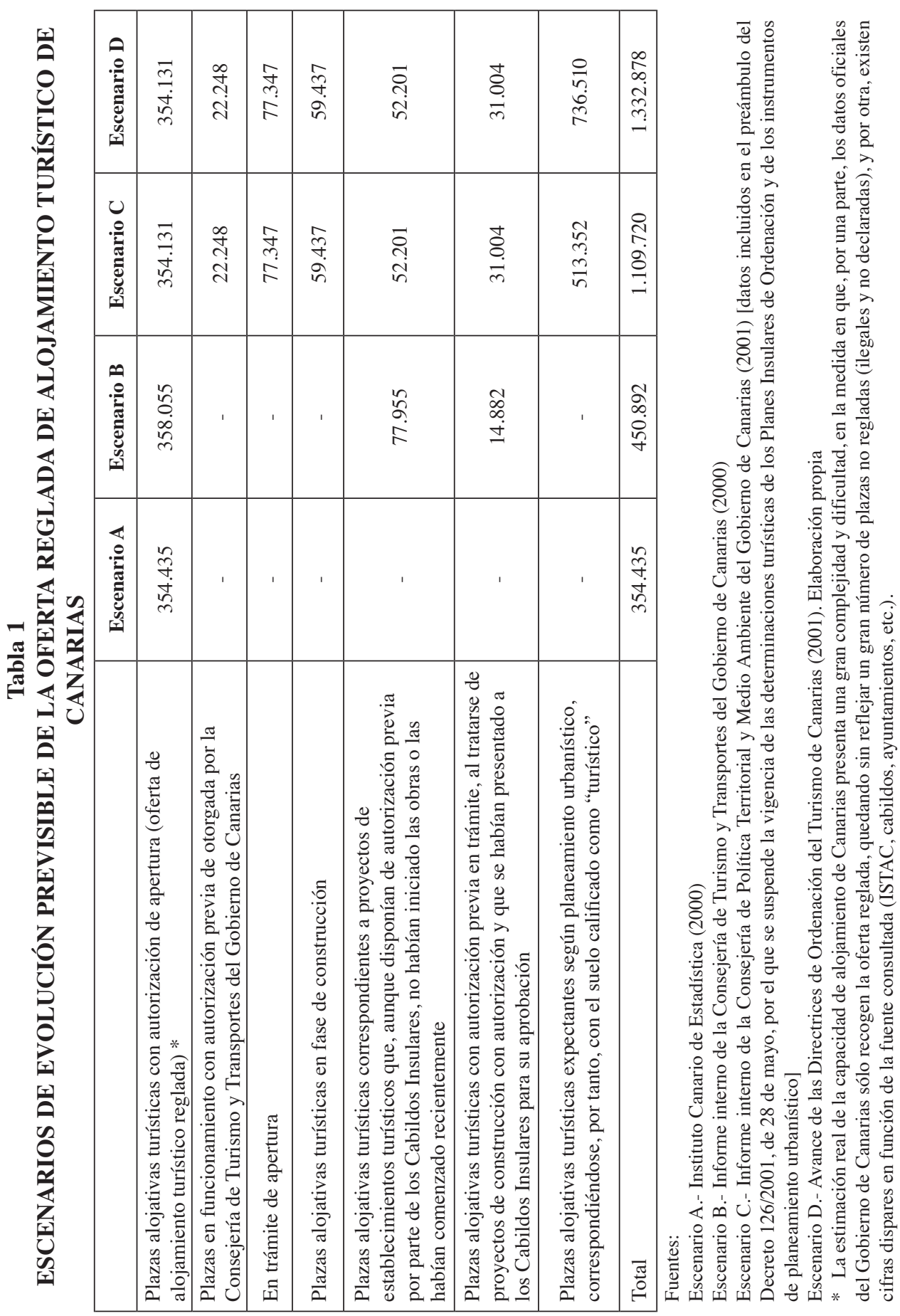


No obstante, consideramos que estos supuestos exploratorios de incremento de la capacidad de alojamiento turístico estuvieron sobrevalorados, al fundamentarse en suposiciones excesivamente extremas y "catastrofistas". Así, un determinado porcentaje no obtuvieron la preceptiva licencia municipal de obras al resultar normativamente imposible, finalizando el expediente en este punto. Otro porcentaje correspondieron a expedientes cuyo promotor presentó la solicitud con el único objetivo de tener sus expedientes en regla, aunque no tuviera intención de materializarla a corto plazo. Asimismo, una cierta cantidad de autorizaciones previas no se iban a materializar por la propia dinámica del sector turístico o por corresponderse a las denominadas "licencias urbanísticas en cartera" y, por tanto, a maniobras "meramente especulativas", tan frecuentemente presentes en el sector de alojamiento turístico, sin que, en algunos casos, respondieran a proyectos reales de inversión turística; así, por ejemplo, como se señala en la Memoria del Plan Insular de Ordenación de Tenerife (2002), de los 41 planes parciales turísticos aprobados, 20 no habían registrado ningún tipo de ejecución, 7 un porcentaje de ejecución inferior al $20 \%$ y sólo 14 uno superior al mismo.

A pesar de ello, la mayoría de los expedientes autorizados se ejecutaron después de haber obtenido la autorización turística previa, "reciclándose" en proyectos de ejecución de obra en ese momento, y, por tanto, fuera del ciclo de inversión prevista a corto plazo, entrando a formar parte del mercado turístico. Así, a fecha de 1 de febrero de 2001, prácticamente la mitad (el 48,8\%) se encontraban en construcción (gráfico 3). Asimismo, según los datos del Inventario de campo realizado entre marzo y abril de 2001 por personal del Servicio de Infraestructura Turística de la Consejería de Turismo y Transporte del Gobierno de Canarias (tabla 1), el 34,9\% y el 30,9\% de las 79.668 plazas autorizadas con anterioridad a agosto de 2000 habían comenzado y finalizado las obras, respectivamente (gráfico 4). Por tanto, 7.246 plazas autorizadas con anterioridad a agosto de 2000 y un porcentaje indeterminado de las 52.201 plazas otorgadas con posterioridad por los Cabildos Insulares a partir de la promulgación de la Ley 2/2000 se encontraban pendientes de materialización en enero de 2001.

Desde el punto de vista de la demanda, el problema de la incorporación, real o potencial, al mercado turístico de este elevado número de plazas turísticas radicó en que podía producirse en un momento en el que la afluencia de turistas de origen extranjero comenzó a descender. Así, en 1999 comenzaron a detectarse signos de estancamiento, que se transformaron en una cierta desaceleración a partir de 2001, hasta el punto de que las cifras de afluencia de 2004 se asemejaron a las registradas en 1998, dando cuenta del inicio de lo que podríamos denominar una "crisis de demanda" (gráfico 5). Esta circunstancia suponía un problema si consideramos que las dos previsiones contenidas en el Informe interno de la Consejería de Política Territorial y Medio Ambiente del Gobierno de Canarias (2001) requerían de una afluencia anual para favorecer una ocupación y una rentabilidad mínima de 17.652.492 turistas (extranjeros y nacionales) para el techo de alojamiento turístico susceptible de concretarse en los siguientes tres años y de 32.847.712 para el contemplado en las previsiones del planeamiento urbanístico; ello hubiera superado la afluencia del año 2000 en un 46,6\% y 172,7\%, respectivamente. Sin embargo, ambos umbrales eran absolutamente inalcanzables por razones de logística e infraestructuras, sobre todo, si tenemos en cuenta que el récord histórico de afluencia de turistas a Canarias alcanzado en el año 2016, en un momento de una extraordinaria coyuntura de recuperación de la demanda, 
sobre todo, la extranjera, como consecuencia de las revoluciones y protestas en el mundo árabe iniciadas en 2010, ésta no superó los quince millones de turistas.

\section{GRÁFICO 3 \\ ESTADO DE LAS PLAZAS ALOJATIVAS TURÍSTICAS CON \\ AUTORIZACIONES PREVIAS OTORGADAS A 1 DE FEBRERO DE 2001}

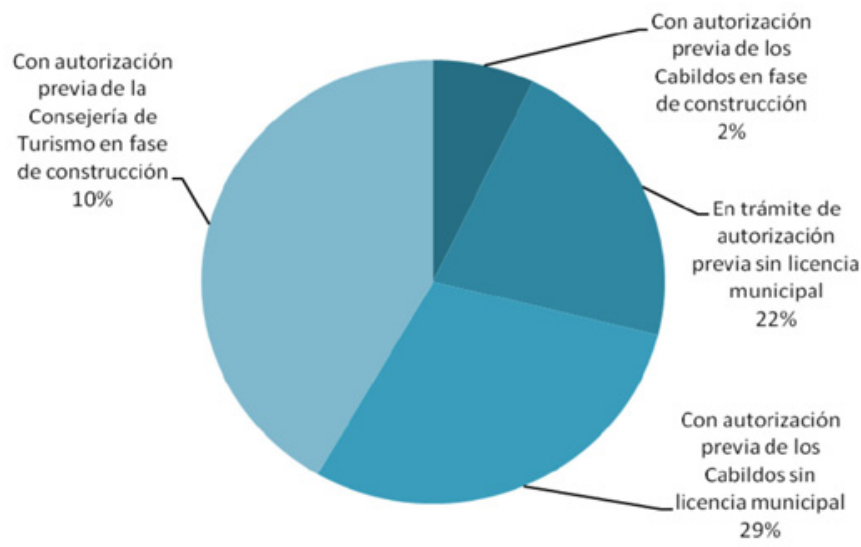

Fuente: Consejería de Turismo y Transporte del Gobierno de Canarias. Elaboración Propia.

\section{GRÁFICO 4 \\ ESTADO DE LAS PLAZAS ALOJATIVAS TURÍSTICAS CON AUTORIZACIONES PREVIAS OTORGADAS}

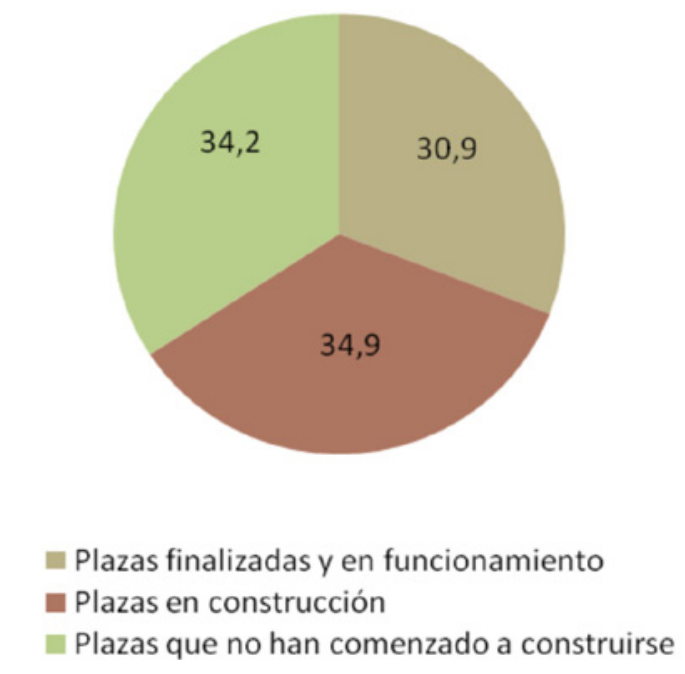

Fuente: inventario de campo realizado entre marzo y abril de 2001 por el Servicio de Infraestructura Turística de la Consejería de Turismo y Transporte del Gobierno de Canarias. Elaboración Propia. 


\section{Gráfico 5 \\ Evolución de la afluencia de turistas a Canarias (1997-2008)}

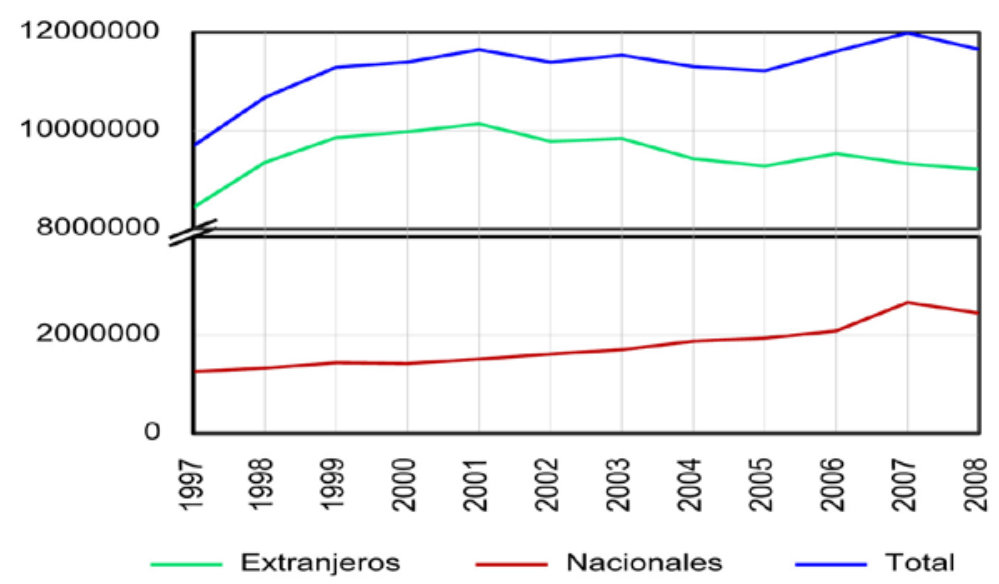

Fuente: ISTAC

Este estancamiento conllevó un riesgo de sobreoferta de alojamiento turístico para la demanda capturable. Esta fue susceptible de tener importantes repercusiones sobre el precio y la calidad de los mismos - y, por ende, del destino-, en cuanto podía hacer aflorar en el mercado un conjunto de alojamientos comercializados a precios tan reducidos, que, en algunos casos, no hubieran permitido siquiera cubrir los costes fijos y, por consiguiente, garantizar la estabilidad financiera o el mantenimiento y reposición adecuada del activo inmovilizado. La posible consecuencia inmediata era una pérdida de capacidad de atracción, competitividad, cuota de mercado y rentabilidad empresarial, con el consiguiente impacto sobre los principales indicadores del negocio turístico y de la rentabilidad empresarial (número de pernoctaciones, estancia media, índices de ocupación, tarifa media diaria, ingreso medio diario por habitación disponible y ocupada, etc.).

La necesidad de corregir este exceso de oferta de alojamiento turístico - con el consiguiente desfase entre la oferta y la demanda - y, sobre todo, gestionar la incertidumbre generada por su crecimiento exponencial y la avalancha de autorizaciones solicitadas a escala insular tras el traspaso de competencias en virtud de la Ley 2/2000, dio lugar a un intenso debate articulado en torno a la "desregulación liberalizadora del mercado versus intervencionismo público"; el Gobierno de Canarias optó finalmente por este último. Así, se promulgó el Decreto 4/2001, de 12 de enero, por el que se acordó la formulación de las Directrices de Ordenación General y las del Turismo, iniciándose un proceso de regulación pública de la oferta de alojamiento turístico y del suelo turístico por parte del Gobierno de Canarias denominado coloquialmente como "moratoria turística canaria". Su efectividad sobre el crecimiento de la oferta de alojamiento turístico de la estrategia de moratoria turística resulta indudable, al impedir que se ejecutasen 143.133 plazas (Simancas, 2015). Para comprobar esta afirmación debemos partir de la posibilidad real 
que un total de 215.388 plazas turísticas pudieron incorporarse al mercado turístico, al tratarse de plazas que habían obtenido la preceptiva autorización previa antes (el 61,2\% de las plazas) o durante (el 38,8\%) la primera y segunda etapa (2003-2009) de la moratoria turística (Simancas, 2015); en la medida en que eran plazas susceptibles de entrar en el mercado turístico en cualquier momento, existió la posibilidad, al menos teórica, de que la capacidad alojativa se incrementase hasta 569.823 plazas respecto a las registradas a 31 de diciembre de 2000. De esta manera, según los datos del Turidata (Gobierno de Canarias), de las 350.484 plazas turísticas existentes en 1999 se pasó a 427.182 en 2009, lo que supuso un incremento sólo del $21,7 \%$. Así, la primera etapa de la moratoria turística (2001-2003) y, en su caso, de la Ley 19/2003, de 14 de abril, por la que se aprueban las Directrices de Ordenación General y del Turismo de Canarias, que inició la segunda etapa (2006-2009) ha funcionado como una estrategia de intervención anticíclica, propia de cualquier política keynesiana, vertebrando límites y ritmos al crecimiento del alojamiento turístico, dirigida a limitar y controlar la entrada al mercado del elevado volumen de plazas turísticas autorizadas durante el tercer boom turístico, y, por tanto, como una solución "remedial" y de "enfriamiento" de esta etapa de urbanismo turístico expansivo.

\section{ALGUNOS FACTORES EXPLICATIVOS DEL TERCER BOOM TURÍSTICO Y DEL URBANISMO EXPANSIVO EN EL LITORAL CANARIO: LA CONVER- SIÓN DE LA ACTIVIDAD TURÍSTICA EN UNA BURBUJA INMOBILIARIA}

Si bien sobre el tercer boom turístico incidieron algunos factores exógenos como las devaluaciones de la peseta de 1992, 1993 y 1995, la estabilidad macroeconómica en Europa y España y la inseguridad en el Mediterráneo derivada de diversos acontecimientos bélicos acaecidos durante la primera mitad de los años noventa (primera Guerra del Golfo, contienda de los Balcanes, conflicto árabe-israelí, etc.) (Hernández, 2010), el comportamiento propio del mercado inmobiliario constituyó el principal desencadenante y, sobre todo, el binomio "turismo-construcción", con el consiguiente predominio, entre otros factores, de la dimensión netamente especulativa y de inversión perfecta, la imposible devaluación del suelo, la revalorización asegurada con cada intermediación, la falta de gobernanza, una dependencia económica del sector de la construcción y el crecimiento continuo de las operaciones inmobiliarias (Burriel, 2008; Murray y Blázquez, 2009; Romero, 2011)). Así, siguió la lógica del despilfarro como estrategia para competir (Rueda, 2002), siguiendo la premisa de la búsqueda de la maximización del beneficio empresarial del denominado tsunami urbanizador de la burbuja inmobiliaria (García, 2005; Fernández Durán, 2006; Gaja, 2008).

En cualquier caso, el importante volumen de solicitudes de autorizaciones turísticas previas y de plazas turísticas construidas en un período tan corto dan cuenta del "recalentamiento" del negocio inmobiliario que, en la mayoría de las ocasiones, precede al turístico. Como ha sucedido en otros destinos turísticos, se trataron de expectativas que obedecieron más a planteamientos vinculados al corto plazo y a la seguridad que ofrece el modelo ya conocido, que a un ajuste adecuado al escenario existente (Santos y Fernández, 2010). Asimismo, supuso una reacción al planteamiento propio de la teoría económica que, ante un aumento de demanda, el ajuste, vía cantidades, se hizo a través de solares 
urbanizados que se encontraban vacíos o de mejoras en suelos que solamente requerían algunas actuaciones de urbanización para convertirse en los mismos; ello se debe a que, como es habitual, la oferta a corto-medio plazo en el mercado del suelo fue relativamente más inelástica y limitada, originándose el ajuste principalmente vía precios, mientras que a largo plazo su elasticidad, aunque reducida, fue mayor.

Ello fue consecuencia de unas condiciones cambiantes que podríamos denominar como "reactivas y perturbadoras", vinculadas, en su mayoría, con circunstancias ajenas a la dinámica del propio sector turístico; nos referimos al papel desempeñado por las corporaciones municipales en la generación de expectativas urbanísticas y a la extraordinaria disponibilidad de capitales procedentes de fuentes privadas y públicas.

\subsection{La gestión especulativa-urbanística de la actividad turística por parte de los ayuntamientos}

Los ayuntamientos concebían a las áreas turísticas como meras "máquinas de crecimiento económico", que ofrecían oportunidades de inversión - fijación espacial y movilización de capital - , que, a su vez, posibilitaban beneficios rápidos mediante el despliegue de planeamiento urbanístico desde una perspectiva neoliberal (Swyngedouw, Moulaert y Rodríguez, 2002). Ello hizo que la actividad turística del tercer boom turístico fuera subsidiaria de la dimensión especulativa-inmobiliaria del negocio turístico. Esta actitud fue consecuencia de la convergencia de una serie de factores.

\subsubsection{La lógica del laissez faire, laissez passer de los ayuntamientos turísticos}

Se dio la paradójica coincidencia temporal del inicio del tercer boom turístico canario con la aprobación de la Ley 7/1995, de 6 de abril, de Ordenación del Turismo de Canarias, modificada por la Ley 7/1997, de 4 de julio, de Ordenación del Turismo de Canarias, actualmente derogada, por la Ley 5/1999, de 15 de marzo. Además de reunir en un texto único una serie de regulaciones dispersas relativas a las condiciones mínimas de la actividad y las infraestructuras que las soportan, con especial atención a las de alojamiento (Parreño y Díaz, 2010), esta norma marcó un punto de inflexión en la política turística de Canarias, enajenando competencias que hasta ese momento eran exclusivas de las entidades insulares. Así, aunque la competencia legislativa en el sector del turismo en Canarias era - y es - una materia exclusiva del Gobierno Autonómico, la Ley 7/1997 culminó el traspaso de competencias urbanísticas a los ayuntamientos. Como señala Jiménez (2008), "esta consagración del principio de la autonomía municipal dio lugar, en general, a la desaparición de los criterios de oportunidad política en los mecanismos de control de las demás administraciones públicas sobre los municipios y a su sustitución por meros controles de legalidad".

Estas Corporaciones Locales resultaron claves para rescatar los derechos urbanísticos, evitando que el crecimiento de la oferta de alojamiento turístico quedara prefijado de antemano. Lo mismo sucedió con su competencia para reaccionar ante los eventuales incumplimientos del sistema de planeamiento urbanístico. Sin embargo, su comportamiento fue justamente el contrario. Así, en lugar de adaptar los planes a la legislación 
vigente o hacerlos efectivos, aplicar los mecanismos finalistas de ejercicio de las competencias de las que eran titulares, declarar la caducidad de los derechos urbanísticos cuando se hubieran incumplido deberes o plazos, así como combatir el fraude alojativo (plazas ilegales), los ayuntamientos favorecieron la aplicación de la lógica del laissez faire, laissez passer, en coherencia con el planteamiento de López Palomeque (1999) de que "la mejor política turística es la que no existe". De esta manera, el inicio y desarrollo del tercer boom turístico se vio favorecido por el hecho de que los instrumentos de planificación territorial y, sobre todo, los de planeamiento urbanístico, general y parcial, se revelaron como tardíos soportes legales dirigidos a legitimar tales expectativas empresariales como derechos, llegando, incluso, a ser generadores de las mismas, vía clasificación del suelo, con la consiguiente posibilidad de ulterior de desarrollo a través de planes parciales de segregación y venta de parcelas.

Esta última situación se vio incentivada por la obcecación de la administración municipal de crear nuevos espacios turísticos como estrategia de rejuvenecimiento de las áreas turísticas consolidadas, en consonancia con el habitual hábito de priorizar la inversión en nuevos crecimientos megalómanos (Burriel, 2008). Ello se vio favorecido por la enorme, en términos relativos, oferta de suelo disponible en las "periferias" de las áreas turísticas consolidadas o en los municipios, hasta ese momento, no consolidados turísticamente y que eran susceptibles de albergar nuevos desarrollos turísticos. Así, la estrategia de casi la totalidad de los instrumentos de planeamiento urbanístico fue la de lograr el crecimiento acelerado del suelo urbanizable con destino turístico, en función de unas proyecciones absolutamente desmesuradas y frívolas. Ello explica que los municipios turísticos o los que estaban en su hinterland fueran los que en durante ese mismo período experimentaron un mayor crecimiento (García Márquez, 2010); así, para un valor inicial de 100, éstos fueron, por orden decreciente, Antigua (370), Pájara, La Oliva, Adeje, San Miguel, Yaiza, Puerto del Rosario, Tuineje, Arona y Mogán (193).

Por tanto, los propios ayuntamientos contravinieron los planes urbanísticos aprobados. Asimismo, fueron enormemente condescendientes y permisivos respecto al incumplimiento de los compromisos de los promotores, la concesión de nuevas licencias, así como la prórroga de antiguas autorizaciones y, sobre todo, de los plazos de ejecución de las licencias nunca ejecutadas; su observación y sanción hubiera supuesto la desclasificación o adecuación de los planes afectados. Ello explica la entonces habitual utilización acomodaticia por parte de los ayuntamientos de la figura del Convenio Urbanístico sin que tuvieran un soporte legal, lo cual se produjo por primera vez con la promulgación de la derogada Ley 9/1999, de 13 de mayo, de Ordenación del Territorio de Canarias, o las modificaciones puntuales del planeamiento o las recalificaciones de suelo; de esto modo, Canarias no fue ajena a lo sucedido en las áreas turísticas de litoral españolas (Vera, 1990).

Otro factor decisivo fue la tardía aprobación definitiva de los Planes Insulares de Ordenación, derivados de la Ley 1/1987, de 13 de marzo: a excepción del Planes Insulares de Ordenación de Lanzarote, que fue el primero en aprobarse (1991), los de Fuerteventura (2001), Tenerife (2002), El Hierro (2002) y Gran Canaria (2003) se retrasaron en exceso, o no llegaron a aprobarse definitivamente hasta el año 2011 (La Palma y La Gomera). Éstos debían definir los criterios, orientaciones y límites razonables, cuantitativos, cualitativos o de localización del turismo. Esta ausencia de referencia de instrumentos de planificación 
territorial hizo que los proyectos turísticos se limitasen a su inclusión en los preceptivos planes urbanísticos, sin coherencia y visión de conjunto a escala insular. Por el contrario, la ordenación territorial del turismo quedó relegada a las decisiones municipales $-\mathrm{y}$, por tanto, a los instrumentos de planeamiento urbanístico (escala municipal, con carácter esencialmente operativo), general y parcial-, que se beneficiaron de la generalizada descoordinación entre los planeamientos de un mismo segmento litoral y de ellos con los instrumentos de planificación territorial; de esta manera, se aprovecharon de las fricciones institucionales, sobre todo, respecto al interfaz regional-local, en materia de planificación urbanística-territorial. Ello favoreció una dispersión - municipalización - de la toma de decisiones estratégicas, así la actitud habitual fue la de asumir una forma de actuar básicamente reactiva, a través de la cual la Administración Pública enmendara a posteriori los problemas o fallos que presenta dicha hegemonía del mercado.

Esto último se complicó debido a que ninguno de los diecisiete municipios turísticos canarios (consolidados o en vía de consolidación), supuestamente los más dinámicos y los que necesitan revisar constantemente sus modelos territoriales, contaban con planes generales aprobados definitivamente. Además, diez tenían un plan aprobado con anterioridad al Decreto Legislativo 1/2000, de 8 de mayo, por el que se aprueba el Texto Refundido de las Leyes 9/1999, de Ordenación del Territorio de Canarias, y 12/1994, de Espacios Naturales de Canarias. A este respecto, resulta llamativo que la ordenación urbanística del municipio de Yaiza seguía rigiéndose por un plan general de ordenación urbana de 1973, no estando, por tanto, ni siquiera adoptado al Texto Refundido estatal de 1976 (García Márquez, 2011), a la vez que los de Mogán, La Oliva y Teguise lo hacían por las Normas Subsidiarias aprobadas en 1998, 1991 y 2001, respectivamente.

Todo lo anterior favoreció un descontrolado proceso de clasificación ex novo de suelo urbanizable con destino turístico, sin apenas control por parte de la administración pública supramunicipal y, por tanto, una enorme cantidad de suelo turístico, ajena a la demanda real, amparados en una visión puramente especulativa, cortoplacismo y de retorno inmediato. Ello originó nuevos desarrollos turísticos, más acordes a las preferencias del momento de la demanda y con mejores condiciones de explotación, con el consiguiente incremento de la oferta de alojamiento turístico y el consumo de suelo en lugares alejados a los núcleos turísticos preexistentes, donde hasta ese momento no se había producido un desarrollo turístico o era incipiente, provocando su incorporación definitiva al mercado turístico. El resultado fue la aparición de procesos análogos al "ciclo de tierra quemada" (Llorca, 2010), consistentes en el consumo de suelo $\rightarrow$ amortización $\rightarrow$ abandono. Además, existió una reducida capacidad de adaptación a los cambios de la demanda de la creación de nueva oferta de alojamiento turístico, debido, sobre todo, a que se encontraba adjudicada a priori, impidiendo cualquier posibilidad de reacción para ajustarse a las necesidades reales de la demanda.

Esta ocupación favoreció un cierto proceso de balearización y de litoralización de la franja costera (Observatorio de la Sostenibilidad de España, 2006). Según un estudio realizado en el año 2000 por la empresa pública Cartográfica de Canarias (Grafcan), entre 1987 y 2002, el suelo ocupado por la edificación y la urbanización se multiplicó por 2,7 en Fuerteventura, incrementándose en un $60 \%$ en Lanzarote. Del mismo modo, la tasa de crecimiento de la superficie ocupada por las áreas turísticas de las islas consolidadas 
turísticamente de Canarias fue del 56,6\% entre 1998 y 2009 (García Cruz, 2014). Esta extraordinaria expansión territorial derivó de las tres formas de producción del espacio turístico (Simancas, García, Dorta y Falero, 2011; García Cruz, 2014; Simancas, 2015): el crecimiento de la oferta complementaria (un 13\%), de las zonas residenciales (18\%) y de la oferta de alojamiento turístico (23\%).

\subsubsection{El predominio del urbanismo liberal}

El desarrollo del tercer boom turístico se vio favorecido por unas disposiciones urbanísticas desreguladoras; nos referimos al Real Decreto-Ley 5/1996, de 7 de junio, de medidas liberalizadores en materia de suelo y colegios profesionales, su modificación puntual en virtud del Real Decreto-Ley 4/2000, de 23 de junio, de Medidas Urgentes de Liberalización en el Sector Inmobiliario y Transportes, y, sobre todo, a la celebérrima Sentencia 61/1997, de 20 de marzo, del Tribunal Constitucional, respecto al Decreto Legislativo 1/1992, de 26 de junio, por el que se aprueba el Texto Refundido de la Ley sobre Régimen de Suelo y Ordenación Urbana. Desde la defensa del derecho de todo propietario a urbanizar, éstas posibilitaron un crecimiento de nuevas urbanizaciones turísticas, así como desbloquear los proyectos paralizados en planes urbanísticos. Así, como es sabido, el Decreto Legislativo 1/1992 fijó la inconstitucionalidad de gran parte del mismo por razones estrictamente competenciales, al tiempo que reafirmó las competencias legislativas de las Comunidades Autónomas en este ámbito; al carecer la Comunidad Autónoma canaria de una legislación urbanística completa propia, hubo que recuperar el Real Decreto 1.346/1976, de 9 de abril, por el que se aprueba el Texto Refundido de la Ley sobre Régimen del Suelo y Ordenación Urbana, y, por tanto, una norma preconstitucional, que lógicamente no se correspondió con la realidad territorial de aquel momento.

Esta situación se complicó con la entrada en vigor de la Ley estatal 6/1998, de 13 de abril, sobre Régimen del Suelo y Valoraciones, que, concebida como la normativa legal básica reguladora de los usos del suelo, obligó a las Comunidades Autónomas a desarrollar una normativa propia; como es sabido, la Ley 9/1999, de 13 de mayo, de Ordenación del Territorio de Canarias, que fue derogada por el vigente Decreto Legislativo 1/2000, se promulgó para el caso de Canarias. Lejos de legislar un modelo diferente al planteado en dicha Ley 6/1998, esta norma adoptó ciertos principios de liberalización y fomento de los procesos inmobiliarios en los ámbitos territoriales de su competencia. Ello explica la modificación puntual del año 2000 de la Ley 6/1998 que posibilitó que el desarrollo urbanístico de los denominados "suelos urbanizables no delimitados" se activasen a partir del momento de que la "iniciativa particular" formulase la previa delimitación y definición de condiciones de desarrollo. Ello dio lugar a un amplio espectro de derechos susceptibles de estar consolidados y extremadamente "blindados".

Lo mismo sucedió con la falta de la especificidad jurídica de un urbanismo turístico, el cual se encauzó a través del ordenamiento aplicable al urbanismo convencional (Vera, 1990). De esta manera, los proyectos turísticos construidos se correspondieron con aspiraciones e intereses empresariales concretos y, en algunos casos, anacrónicos, desligados de un modelo de explotación conjunto y adecuado del modelo de desarrollo territorial en que se debían insertar. Ello explica el crecimiento cartesiano, "en mancha de aceite", 
de las urbanizaciones turísticas, en las que se priorizó el proyecto - en detrimento del plan-, con la consiguiente materialización territorial como piezas aisladas, fragmentadas e inconexas entre sí, sin visión de conjunto del espacio turístico.

En este contexto, los ayuntamientos contribuyeron a maximizar el volumen de producción (los alojamientos turísticos) a través de un "urbanismo por proyectos", flexible o "a la carta" (Rullán, 2014). Del mismo modo, favorecieron un desarrollo territorial del turismo basado en "proyectos de producción inmobiliaria" más que en "proyectos de explotación turística". Además, en coherencia con lo sucedido en otros ámbitos territoriales (Murray, Blázquez y Amer, 2010; Romero, 2012), los agentes privados acordaron cambios en el planeamiento urbanístico en un contexto de negociación bilateral y asimetrías de información, generando redes pro-crecimiento locales, a menudo clientelares y corruptas.

Por consiguiente, el tercer boom turístico canario se desarrolló en el marco de lo que Díaz y Lourés (2008) han denominado como "urbanismo neoliberal". Este favoreció las pretensiones urbanizadoras-inmobiliarias en coherencia con el principio de "todo urbanizable" (Fernández Durán, 2006), contenido en la propia Exposición de Motivos de la Ley 6/1998. Con ello se favoreció un planeamiento urbanístico dirigido, en su mayoría, a eliminar cualquier barrera que dificultara u condicionara un desarrollo territorial del turismo liderado esencialmente por el mercado $-\mathrm{y}$, por ende, por la voluntad, los intereses y la capacidad de la iniciativa privada - , y, por tanto, cualquier restricción propia de las regulaciones.

\subsubsection{El urbanismo turístico como una forma de recaudación municipal}

La reducida capacidad financiera de los ayuntamientos, sobre todo, tras dejar exentas a las personas físicas en el Impuesto de Actividades Económicas en virtud de Ley 51/2002, de 27 de diciembre, de Reforma de la Ley 39/1988, de 28 de diciembre, Reguladora de las Haciendas Locales, hizo que el urbanismo turístico se utilizara, al menos parcialmente, como un mecanismo para maximizar los ingresos fiscales, los cuales resultan directamente proporcionales a sus competencias en esta materia. Ello se debió a que esta norma favoreció que los municipios se dotasen de una estructura recaudatoria propia basada en la imposición sobre el suelo - en concreto, la capacidad de calificarlo- en su doble mecanismo tributario de tenencia y plusvalías, con el fin de asegurar un grado aceptable de autonomía fiscal (Bergasa, 2004). De esta manera, la actividad turística se reveló como su principal fuente de ingresos económicos, en cuanto generaba en torno al $35 \%$ de los ingresos de las Administraciones Públicas (1.500 millones de euros) y absorbía el 12,7\% del gasto público (898 millones de euros) (Consejo Económico y Social, 2001).

En paralelo, la reducción de la capacidad de las instituciones públicas autonómicas e insulares para controlar los flujos de capital hizo que las inversiones tomaran frecuentemente la forma de "mecanismo de negociación entre el capital financiero transnacional y los gobiernos locales" (Harvey, 1989: 5), derivando en el desencadenamiento de dicha competencia intermunicipal por la atracción de inversiones. Como plantea Bauzá (2009: 21), "más que un cambio de modelo, lo que se produce es la aparición de una solución espacio-temporal a la sobreacumulación de capital generada por el turismo de masas: el negocio turístico-inmobiliario". Ello explica que la mayoría de los ayuntamientos con posibilidades de lograr un desarrollo territorial del turismo en su litoral operasen de una 


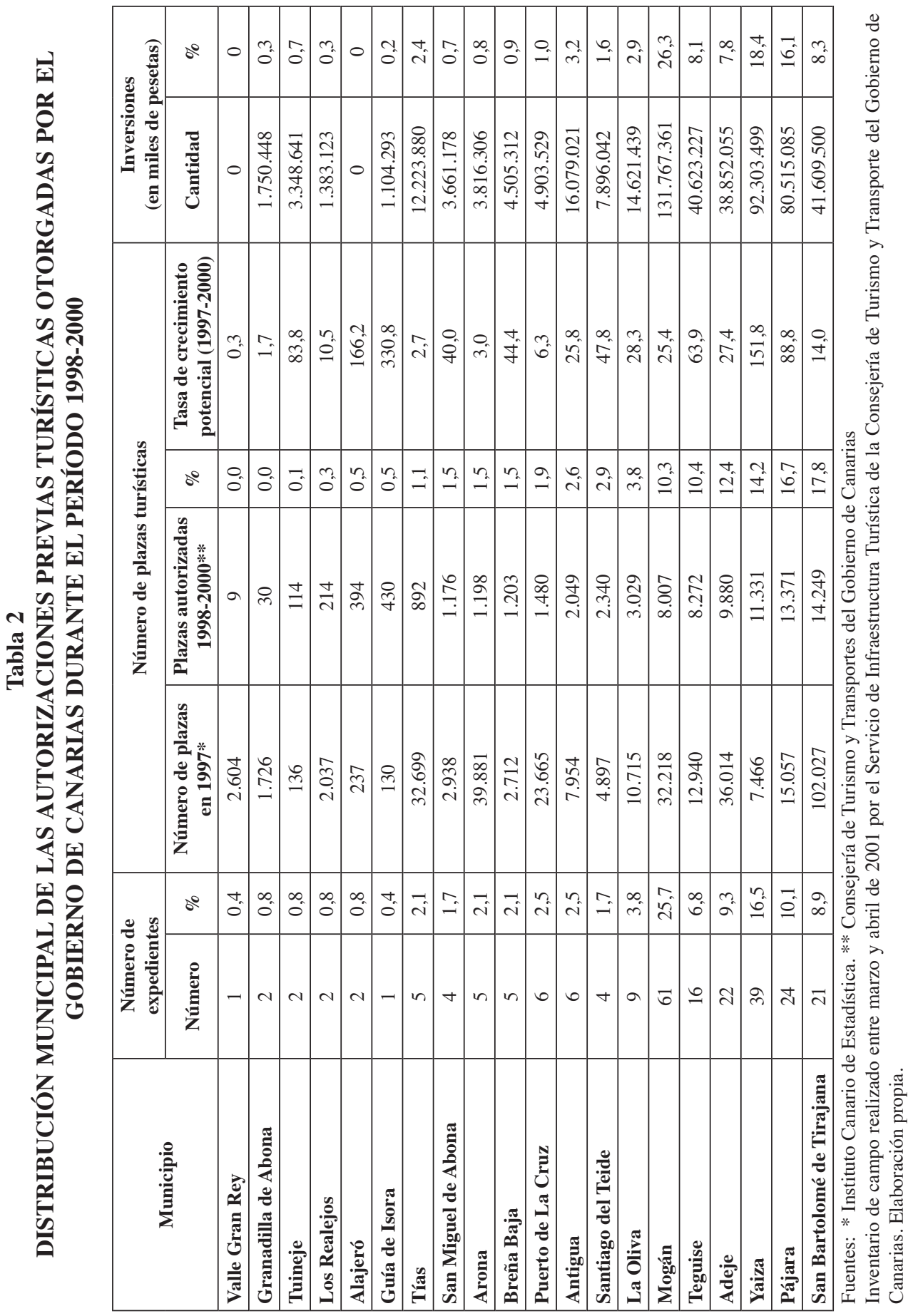


manera autónoma, a modo de "reinos de taifas", intentando atraer proyectos turísticos, con la consiguiente competencia intermunicipal. Así, las expectativas extraordinarias de crecimiento turístico generadas en el tercer boom turístico se concentraron básicamente en 19 de los entonces 87 municipios; de ellos, once concentraron el 93,5\% del total de plazas regladas de alojamiento turístico del Archipiélago y de los que únicamente tres (San Bartolomé de Tirajana, Adeje y Arona) acapararon el 50,3\%. Asimismo, tan sólo seis, San Bartolomé de Tirajana y Mogán (Gran Canaria), Pájara (Fuerteventura), Yaiza y Teguise (Lanzarote) y Adeje (Tenerife) acumularon el 81,8\% de las autorizaciones turísticas previas favorables emitidas por la Consejería de Turismo y Transportes del Gobierno de Canarias entre el 1 de enero de 1998 y el 18 de agosto de 2000 (tabla 2).

Lo anterior explica la dependencia de los "municipios turísticos" de los ingresos procedentes de impuestos vinculados con el binomio turismo-construcción, aunque de diferente forma: mientras en los más colmatados casi el $70 \%$ de los ingresos procedían del Impuesto de Bienes Inmuebles (Fernández Tabales, 2004), en los municipios en fase de crecimiento de otros conceptos de naturaleza urbanística (licencias urbanísticas, aprovechamientos urbanísticos, impuesto de instalaciones, construcciones y obras, enajenaciones del patrimonio municipal de suelo, etc.). Asimismo, generó un problema de asimetría de ingresos y gastos de diferentes niveles en el denominado "federalismo fiscal": mientras los ayuntamientos se beneficiaban de las prebendas derivadas del desarrollo inmobiliario-turístico, la Administración autonómica tuvo que asumir los gastos derivados en infraestructuras, equipamiento y prestación de los servicios públicos

\subsection{Las excepcionales condiciones de financiación del crecimiento turístico: la acu- mulación de capitales procedentes de fuentes privadas y públicas}

\subsubsection{Las fórmulas de financiación privada}

El mencionado informe interno de la Consejería de Turismo y Transportes del Gobierno de Canarias (2000) señala que la tasa de crecimiento de las inversiones en los alojamientos turísticos fue del 61,5\% entre 1998 y 1999, pasando de 67.428.200.000 a 109.634.773.000 pesetas. Asimismo, según los datos recopilados de los expedientes de autorizaciones previas otorgadas por la Consejería de Turismo y Transportes entre 1998 y 2000, la inversión de los proyectos solicitados (nueva construcción de alojamientos turísticos, modificación de proyecto de construcción y reformas) ascendió a 500.963.939.000 pesetas. Esta jerarquización de objetivos durante esta primera etapa del tercer boom turístico hizo que la construcción de nueva oferta de alojamiento turístico se antepusiera a las operaciones de renovación de la existente; prueba de ello es que, según el citado informe interno, únicamente el 1,3\% de la inversión turística se dedicó a obras de renovación edificatoria en los años 1998 y 1999.

Aunque la llegada de capitales como consecuencia del bloqueo al incremento de la oferta de alojamiento turístico de las Islas Baleares constituyó un factor importante, la liberalización del mercado crediticio resultó un factor decisivo, dando lugar a una relación "recursos propios-recursos ajenos" relativamente baja. Ésta se vio animada por la disponibilidad de financiación suficiente por parte del sistema bancario, con unos tipos 
de interés relativamente bajos, que, en muchos casos, sobrepasaron los límites habituales de prudencia financiera; así, una gran cantidad de proyectos turísticos se financiaron pensando más en la rentabilidad inmobiliaria de la inversión que en su futura viabilidad turística. Ello se completó con el continuo descenso del coste del dinero y su mantenimiento a un nivel muy bajo, históricamente desconocido (Burriel, 2008), así como la elevada relación préstamo/valor (Fernández y Cruz, 2011). Por tanto, los promotores dispusieron de abundante dinero barato desde mediados de la década de los noventa (Rullán y Artigues, 2007). De esta manera, la expansión territorial del desarrollo turístico del tercer boom turístico fue una materialización de la reproducción ampliada de los circuitos de capital planteados por Harvey (1985), mediante la cual el exceso de dinero circulante se ha dirigido al circuito secundario de capital (Lois et al., 2016).

Todo lo anterior acentuó lo que Navarro y Becerra (1992) han denominado como "desempresarialización" de la actividad turística, en cuanto el promotor de la construcción de un alojamiento turístico no tenía, en la mayoría de los casos, la intención de asumir su explotación, relegándola a las grandes cadenas hoteleras o holdings a través de fórmulas de franquicia, contratos de arrendamiento, de explotación, de gestión o similares. Esta flexibilización de las figuras empresariales permitió la separación entre propiedad y gestión, con la consiguiente entrada de capitales ajenos al sector turístico (por ejemplo, constructores, cajas de ahorros, etc.). Así, se generó una relación rentable: mientras que estos últimos aportaron el suelo, las relaciones con los poderes locales y la financiación parcial o total del alojamiento turístico, las cadenas hoteleras que asumían la gestión aportaban su know-how, sus canales de distribución, las economías de escala y de alcance de distinto tipo (entre otras, compra de suministros, costes operativos y administrativos, publicidad y propaganda, estudios de mercado o los sistemas de reservas, el control y el poder de negociación frente a las agencias de viajes, turoperadores o centrales externas de reservas).

Sobre esta disponibilidad de financiación privada también incidió la distorsión del equilibrio natural entre costes y beneficios empresariales. Este derivó del ajuste de la oferta de alojamiento turístico que se produjo con la paralización de nuevos proyectos durante la etapa de recesión 1989-1993. Ello facilitó la recuperación de los beneficios y de los índices de ocupación en los establecimientos hoteleros.

Igualmente decisivas resultaron las expectativas de rentabilidad derivadas de los intensos crecimientos de la demanda de la segunda mitad de los años noventa y del escaso retorno de otros activos susceptibles de atraer el ahorro empresarial y familiar, en un momento de inicio de caídas en las cotizaciones de los valores bursátiles y de bajos tipos de interés de los activos de renta fija, el blanqueo de capitales ocultos con la entrada en el euro, así como el arraigo social del desarrollismo y sus beneficios aparentes (Burriel, 2008). A ello hay que añadir la excepcional acumulación de capitales que se canalizaron hacia el sector inmobiliario y, en concreto, a la construcción de nuevos alojamientos turísticos.

Otro factor decisivo que incidió sobre esta extraordinaria disponibilidad de financiación privada fue la existencia de un mercado turístico tan potente como para que los operadores turísticos (cadenas hoteleras y turoperadores) abonasen por anticipado los beneficios esperados a las empresas constructoras de los establecimientos turísticos, a 
cambio de unas condiciones preferentes y ventajosas de contratación durante un período de garantía. Ello posibilitó que aquéllos pre-financiaran la construcción del establecimiento, al tener una mayor capacidad para la obtención de créditos y el mantenimiento de las pérdidas en alguno de los mismos, ya que los otros pueden soportar con sus beneficios el total empresarial.

A todo lo anterior se añadió el hecho de la mayor parte de la inversión en la construcción de los establecimientos de alojamiento turístico, sobre todo, hoteleros, eran susceptible de amortizarse en márgenes de tiempo relativamente cortos, algunos de ellos en cuatro o cinco años; ello se vio favorecido por el hecho de que dicha amortización se producía a lo largo de todo el año y no sólo durante la temporada alta como sucedía en las Islas Baleares. A todo lo anterior se sumaron la obtención de unos importantes márgenes de beneficios; así, por ejemplo, según la Federación Española de Hoteleros, los establecimientos hoteleros canarios eran en 1999 los cuartos del país con mayores ingresos anuales por habitación, con una media de 2.390 .000 pesetas.

\subsubsection{Las fórmulas de financiación pública}

La financiación pública derivó de la existencia de tres tipos de fuentes. Éstas hicieron que la función de estímulo en materia de turismo de la Administración Pública (OCDE, 1989) sustituyó, e incluso, suplantó el papel de la iniciativa privada.

La primera fue el Real Decreto 569/1988, de 3 de junio, de delimitación de la zona de promoción económica de Canarias (vigente hasta el 1 de enero de 2007). Con arreglo a lo dispuesto en el artículo 7.1 del Real Decreto 1.535/1987, de 11 de diciembre, por el que se aprobó el Reglamento de la Ley 50/1985, de 27 de diciembre, de Incentivos Regionales para la Corrección de Desequilibrios Económicos Interterritoriales, prácticamente la totalidad de las subvenciones a fondo perdido concedidas en Canarias durante el período 1996-2002 se dirigieron a la construcción de establecimientos hoteleros -en detrimento de los otros dos supuestos objeto de subvención, esto es, la modernización de la oferta de alojamiento turístico y la construcción de instalaciones complementarias de ocio-, al bonificarse un porcentaje máximo del 50\% sobre la inversión aprobada. En el citado informe interno del Servicio de Infraestructura Turística de la Consejería de Turismo y Transporte del Gobierno de Canarias (2000) se estimó que la concesión de tales subvenciones ascendió a 22.709.146.000 pesetas en noviembre de 2000, lo que supuso una inversión media de 4.429,5 euros por plaza de alojamiento turístico (tabla 3 ).

La segunda fuente de financiación pública se correspondió con los Fondos Estructurales y de Cohesión derivados de la condición de Canarias como Objetivo 1. Según Armesto (2008), Canarias recibió 6.110,7 millones de euros procedentes de fondos europeos entre 1986 y 2006. Éstos tuvieron una importante aplicación en el sector turístico, sobre todo, entre 1998 y 2002, al subvencionar hasta el 25\% de la inversión total de la construcción de un alojamiento turístico hotelero. 
Tabla 3

\section{CUANTÍA DE LAS SUBVENCIONES PROCEDENTES DE LOS INCENTIVOS ECONÓMICOS REGIONALES CONCEDIDAS EN CANARIAS EN VIRTUD DEL REAL DECRETO 569/1988, A FECHA DE NOVIEMBRE DE 2000 (EN MILES DE PESETAS)}

\begin{tabular}{|c|c|c|c|c|c|c|c|}
\hline & \multicolumn{2}{|c|}{$\begin{array}{c}\text { Con supervisión de obra } \\
\text { ejecutada }\end{array}$} & \multicolumn{2}{|c|}{$\begin{array}{c}\text { Con informe de } \\
\text { viabilidad técnica } \\
\text { (obra no comenzada) }\end{array}$} & \multicolumn{2}{|c|}{ Total } & \multicolumn{2}{|c|}{\begin{tabular}{c} 
Relación \\
Plazas \\
\cline { 2 - 9 } subvención/ \\
plaza
\end{tabular}} \\
\hline Fuerteventura & 771.588 & 1.166 & 9.572 .850 & 5.285 & 10.344 .438 & 6.451 & 1.604 \\
\hline Tenerife & 1.065 .661 & 2.404 & 3.966 .801 & 8.885 & 5.032 .462 & 11.289 & 446 \\
\hline Gran Canaria & 1.097 .536 & 1.356 & 3.904 .864 & 7.316 & 5.002 .400 & 8.672 & 577 \\
\hline Lanzarote & 147.414 & 398 & 2.182 .432 & 4.012 & 2.329 .846 & 4.410 & 528 \\
\hline Total & 3.082 .199 & 5.324 & 19.626 .947 & 25.498 & 22.709 .146 & 30.822 & 737 \\
\hline
\end{tabular}

Fuente: Informe interno del Servicio de Infraestructura Turística de la Consejería de Turismo y Transporte del Gobierno de Canarias según datos del entonces Ministerio de Hacienda.

Elaboración propia.

La tercera fuente se refiere a los incentivos fiscales contemplados en la Ley 19/1994, de 6 de julio, de Modificación del Régimen Económico y Fiscal de Canarias, en concreto, la Reserva para Inversiones en Canarias (RIC). Tomando como precedente la figura del Fondo de Previsión para Inversiones y el régimen transitorio establecido por la Ley 20/1991, la RIC constituye uno de los incentivos fiscales propios y exclusivos más potentes de los que conforman el Régimen Económico y Fiscal de Canarias, hasta el punto de que se trata del "incentivo fiscal que más recursos ha conseguido movilizar en las Islas" (Consejo Económico y Social de Canarias, 2010: 60). Su dotación posibilita la obtención de ventajas fiscales, en cuanto permite reducir la base imponible hasta un $90 \%$ de los Beneficios No Distribuidos en el Impuesto de Sociedades o del Impuesto sobre la Renta de las Personas Físicas por el importe que destinen de sus beneficios, sin previo pago de los mismos; la única condición establecida es que esas cantidades sean materializadas dentro de los tres años siguientes al devengo del correspondiente impuesto por parte de empresas canarias, entendidas como aquellas con establecimiento permanente en las Islas y, por tanto, que desarrollen su actividad en este ámbito territorial. Así, la RIC se convirtió en una fuente de financiación patrimonial para la actividad turística, al entenderse como una forma de materialización relacionada contablemente con la adquisición de activos fijos. Ello se debió que su materialización en suelo turístico, edificado o no, en forma de construcción de nuevos alojamientos turísticos, "encaja como un guante" (Villar, 2003: 593), dada la libertad interpretativa derivada de su desarrollo regulatorio insuficiente y dudoso, su propia rentabilidad (ahorro) fiscal, así como la posibilidad de que pudiera apli- 
carse en la adquisición de activos fijos situados o recibidos en Canarias. En este sentido, llama la atención la coincidencia temporal (1997) del inicio del tercer boom turístico con el primer plazo fijado de tres años de materialización de las cantidades que dotaban a la RIC; así, en ese año se materializó la mayor parte de la misma, siendo una proporción que creció progresivamente hasta el punto que a partir de 1999 alcanzó su totalidad (tabla 4), lo que prácticamente se repitió hasta 2008, momento en el que comenzó a incidir la crisis económica-financiera internacional y, por ende, el final de una década turística "prodigiosa". Ello explica que las cuantiosas ayudas para la creación de nuevos establecimientos turísticos de alojamiento provocaron que gran número de empresas del sector inmobiliario derivaron sus inversiones a un sector al que hasta entonces no habían prestado atención. Esta orientación turística dada a la RIC ha sido cuestionada desde diversas perspectivas (Déniz, Verona y Rodríguez, 2007; Consejo Económico y Social de Canarias, 2010).

\section{Tabla 4}

\section{EVOLUCIÓN ANUAL DE LAS DOTACIONES A LA RIC EN RELACIÓN CON SU GRADO DE MATERIALIZACIÓN (EN MILLONES DE EUROS)}

\begin{tabular}{|c|c|c|c|}
\hline & $\begin{array}{c}\text { Dotaciones anuales a } \\
\text { la RIC }\end{array}$ & $\begin{array}{c}\text { Cantidades } \\
\text { materializadas }\end{array}$ & $\begin{array}{c}\text { Grado de } \\
\text { materialización } \\
\text { (en \%) }\end{array}$ \\
\hline $\mathbf{1 9 9 4}$ & 490 & 65 & 13,3 \\
\hline $\mathbf{1 9 9 5}$ & 696 & 44 & 6,3 \\
\hline $\mathbf{1 9 9 6}$ & 881 & 325 & 37 \\
\hline $\mathbf{1 9 9 7}$ & 1.019 & 800 & 78,5 \\
\hline $\mathbf{1 9 9 8}$ & 1.466 & 1.466 & 96,6 \\
\hline $\mathbf{1 9 9 9}$ & 1.667 & 1.667 & 100 \\
\hline $\mathbf{2 0 0 0}$ & 1.786 & 1.729 & 96,8 \\
\hline $\mathbf{2 0 0 1}$ & 1.890 & 1.868 & 98,8 \\
\hline $\mathbf{2 0 0 2}$ & 1.949 & 1.595 & 81,8 \\
\hline $\mathbf{2 0 0 3}$ & 2.075 & 2.075 & 100 \\
\hline $\mathbf{2 0 0 4}$ & 2.118 & 2.118 & 100 \\
\hline $\mathbf{2 0 0 5}$ & 2.167 & 2.149 & 99,2 \\
\hline $\mathbf{2 0 0 6}$ & 2.451 & 2.451 & 100 \\
\hline $\mathbf{2 0 0 7}$ & 1.640 & 1.640 & 100 \\
\hline $\mathbf{2 0 0 8}$ & 947,5 & 132 & 14 \\
\hline
\end{tabular}

Fuente: Datos ofrecidos por el Gobierno de España en una respuesta parlamentaria por escrito a Gaspar Llamazares, diputado de Izquierda Unida en el Congreso (febrero de 2011). 


\section{CONCLUSIONES}

El análisis del tercer boom turístico demuestra que su génesis derivó de unas extraordinarias expectativas empresariales, reales y potenciales, de construcción de nuevos alojamientos turísticos. Sin embargo, éstas no respondieron a una demanda real, sino a procesos de especulación urbanística derivadas de unas magníficas condiciones fiscales y económicas, en forma de incentivos públicos, estatales y autonómicos, así como al predominio de los principios de desregulación y liberalización del urbanismo, desarrollado fundamentalmente a escala municipal. Ello explica que estas expectativas de crecimiento de la oferta de alojamiento turístico se generasen sin responder a razones objetivas, de visión de conjunto y sin tener en cuenta las limitaciones del mercado turístico (número de visitantes).

Lo anterior dio lugar a un predominio del crecimiento cuantitativo del turismo. Ello distorsionó "artificialmente" la dinámica natural (tendencial) de la capacidad de alojamiento turístico de Canarias, así como el conveniente equilibrio entre la oferta y la demanda. Este se vio fomentado, sobre todo, por el suelo "liberado" de las protecciones ante la urbanización de las leyes anteriores a 1998 en coherencia con la voluntad y capacidad urbanizadora de la iniciativa privada que operaba en el sector inmobiliario-turístico. Ello dio libertad de acción casi absoluta a los agentes (Rullán, 1995). Así, la producción turística se vinculó estrechamente con la inmediatez del negocio inmobiliario y la especulación del suelo, favoreciendo la improvisación y el "desarrollismo" en detrimento de "desarrollo". El resultado final fue el "triunfo del sector inmobiliario turístico sobre el turístico stricto sensu", como han señalado Bote et al. (1999: 192) en referencia a situaciones similares.

Ello atrajo a entidades mercantiles vinculados, sobre todo, al lobby empresarial de la construcción y la promoción inmobiliaria. Estos consideraron al sector turístico extremadamente atractivo para rentabilizar sus inversiones con recurso propios o procedentes de subvenciones públicas e incentivos fiscales. Así, el tercer boom turístico estuvo liderado, en su mayoría, por promotores urbanísticos en detrimento de los que explotan el negocio turístico con voluntad de permanencia; ello explica que los agentes "productores" de la oferta de alojamiento turístico adquirieran un mayor peso que los actores que la gestionaba. Su principal motivación fue alcanzar el máximo beneficio empresarial en el mínimo tiempo posible, con la consiguiente secuela de mediaciones y distorsiones especulativas que lleva aparejado de por sí el fenómeno urbanístico-inmobiliario. Así, mientras los umbrales de sostenibilidad territorial de los espacios insulares canarios reclamaban la ralentización del crecimiento de la capacidad de alojamiento turístico y la apuesta por su renovación, el estado de optimismo colectivo que generaron el marco financiero-fiscal del momento y el "urbanismo liberal" propiciaron una expansión territorial del espacio turístico sin precedentes.

\section{BIBLIOGRAFÍA}

ARMESTO PINA, J.F. (2008): "El impacto de la política regional comunitaria en Galicia. Una panorámica", Revista Galega de Economía, n 17, pp. 1-18.

ARTIGUES, A. y RULLAN, O. (2007): "Nuevo modelo de producción residencial y territorio urbano disperso (Mallorca, 1998-2006)", Scripta Nova, vol. XI, nº 245 (10). 
BAUTE HERNÁNDEZ, L. y DE SOUZA IGLESIAS, A. (2001): Avance de las Directrices de Ordenación del Turismo. Santa Cruz de Tenerife, Gobierno de Canarias.

BERGASA, O. (2004): "El binomio turismo-construcción en la gestión y financiación de los municipios turísticos", en Turismo y territorio en la sociedad globalizada. Santa Cruz de Tenerife, Ayuntamiento de la Villa de Adeje / Instituto Pascual Madoz del Territorio, Urbanismo y Medio Ambiente / Universidad Carlos III, pp. 287--297.

BLÁZQUEZ, M., MURAY, I y GARAU, J. M. (2002): El tercer boom. Indicadors de sostenibilitat del turisme de les Illes Balears 1989-1999. Centre d'Investigació i Tecnologies Turístiques de les Illes Balears.

BOTE, V., MARCHENA, M. y SANTOS, E. (1999): "La descentralización autonómica y la diversificación de la estrategia de desarrollo turístico (1974-1998)", en Historia de la economía del turismo en España. Madrid, Cívitas, pp. 135-193.

BURRIEL DE ORUETA, E. (2008): "La década prodigiosa del urbanismo español (19972006)", Scripta Nova: Revista electrónica de Geografía y Ciencias Sociales, vol. 12, $\mathrm{n}^{\mathrm{O}} 270$ (64).

BURRIEL DE ORUETA, E. (2014): "El estallido de la burbuja inmobiliaria y sus efectos en el territorio", en Geografía de la crisis económica en España. Valencia, Publicaciones de la Universidad de Valencia, pp. 101-140.

DÉNIZ, J., VERONA, M. y RODRÍGUEZ, R. (2007): “La materialización de la Reserva para Inversiones en Canarias en la protección del medio ambiente, ¿qué ha fallado?", en VI Seminario de Economía Canaria. Las Palmas de Gran Canaria.

DÍAZ FERIA, L., MARTÍN ROSA, M. y LAIZ HERRERAS, N. (2001): Lanzarote 2001. Análisis de la evolución reciente de la edificación y el turismo. Arrecife, Cabildo Insular de Lanzarote.

DÍAZ ORUETA, F. y LOURÉS SEOANE, M. (2008): “La globalización de los mercados inmobiliarios: su impacto sobre la Costa Blanca", Ciudad y Territorio: Estudios Territoriales, $\mathrm{n}^{\mathrm{0}} 155$, pp. 77-92.

DONAIRE, J. y MUNDET I CERDÁN, Ll. (2001): "Estrategias de reconversión turística de los municipios litorales catalanes", Papers de Turisme, $\mathrm{n}^{\circ} 29$, pp. 50-66.

EXCELTUR (2003): Hacia un nuevo paradigma en el modelo de gestión de los destinos del litoral mediterráneo y las islas: los Proyectos de Reconversión Integral de Destinos Turísticos (PRIDET). Madrid, Área de Estudios e Investigaciones de Exceltur.

FERNÁNDEZ DURÁN, R. (2006): El tsunami urbanizador español y mundial. Sobre sus causas y repercusiones devastadoras y la necesidad de prepararse para el previsible estallido de la burbuja inmobiliaria. Barcelona, Virus editorial.

FERNÁNDEZ TABALES, A. (2004): "Turismo y Ordenación del Territorio", Quaderns de Política Econòmica, no 7 , pp. 35-47.

GAJA I DÍAZ, F. (2008): “El 'tsunami urbanizador' en el litoral mediterráneo. El ciclo de hiperproducción inmobiliaria 1996-2006”, Scripta Nova. Revista Electrónica de Geografía y Ciencias Sociales, vol. XII, nº 270 (66).

GARCÍA CRUZ, J.I (2014): El impacto territorial del tercer boom turístico de Canarias. Servicio de Publicaciones de la Universidad de La Laguna. Series Tesis doctoral.

GARCÍA MÁRQUEZ, F. (2010): “La Ordenación del Territorio como práctica pública de articulación de modelos de desarrollo", en El impacto de la crisis en la economía 
canaria. Claves para el futuro. Volumen II. San Cristóbal de La Laguna, Real Sociedad Económica de Amigos del País de Tenerife / Cabildo Insular de Tenerife, pp. 801-842. GARCÍA MÁRQUEZ, F. (2011): "Estado del planeamiento en Canarias", en Estudios sobre planeamiento territorial y urbanístico. Valencia, Tirant Lo Blanch, pp. 17-47.

GARCÍA, J. (2005): "Por una liberalización del paradigma urbanístico español (III): el tsunami urbanístico que arrasará el territorio", Ciudad y Territorio, Estudios Territoriales, XXXVII, $\mathrm{n}^{\circ} 144$, pp. 273-286

HARVEY, D. (1989): "From managerialism to entrepreneurialism. The transformation in urban governance in late capitalism", Geografiska Annaler, vol. 71, n 1, pp. 3-17.

HARVEY, D. (1985): The Urbanization of Capital. Studies on the History and Theory of Capitalist Urbanization. Baltimore, John Hopkins University Press.

HERNÁNDEZ MARTÍN, R. (2010): “Turismo y desarrollo en Canarias. Las bases para un nuevo modelo", en Destinos turísticos maduros ante el cambio. Reflexiones desde Canarias. San Cristóbal de La Laguna, Instituto Universitario de Ciencias Políticas y Sociales. Universidad de La Laguna, pp. 281-305.

HERNÁNDEZ MARTÍN, R. y RODRÍGUEZ FUENTES, C. (2007): "La economía del Turismo. 1960-2000”, en Economía e insularidad (siglos XIV-XX). San Cristóbal de La laguna, Servicio de Publicaciones de la Universidad de La Laguna, pp. 201-238.

JIMÉNEZ SÁNCHEZ, F. (2008): "Boom urbanístico y corrupción política en España", en Modernidad, crisis y globalización: problemas de política y cultura. Fundación Cajamar, $\mathrm{n}^{\circ} 14$.

LOIS GONZÁlEZ, R.; PIÑEIRA MANTIÑAN, Ma y VIVES MIRÓ, S. (2016): “El proceso urbanizador en España (1990-2014): una interpretación desde la geografía y la teoría de los circuitos de capital", Scripta Nova. Revista Electrónica de Geografía y Ciencias Sociales, Vol. XX, n ${ }^{\circ} 539$.

LÓPEZ PALOMEQUE, F. (1999): "Política turística y territorio en el escenario del cambio turístico", Boletín de la Asociación de Geógrafos Españoles, n. 28, pp. 23-38.

MACÍAS HERNÁNDEZ, A. y RIVERO CEBALLOS, J. (2009): "El concepto de crisis económica en la historia de Canarias", Hacienda Canaria, no 29 , pp. 85-104.

MARTÍ, P. y NOLASCO, A. (2011): "La expansión urbanística reciente de la costa alicantina, una realidad constatable", en Geografía y desafios territoriales en el siglo XXI: Urbanismo expansivo: de la utopía a la realidad (Gonzálvez, V. y Marco, J.A., coord.). Alicante, Universidad de Alicante, pp. 367-378.

MARTÍN RUIZ, J.F. (2001): Geografía de Canarias. Sociedad y medio natural. Las Palmas de Gran Canaria, Ediciones del Cabildo de Gran Canaria.

MATA OLMO, R. (2011): “Urbanización reciente y cambios paisajísticos en España. Por una Nueva Cultura del Territorio y un urbanismo renovado", en Ordenación del Territorio y Urbanismo: conflictos y oportunidades. Sevilla, Universidad Internacional de Andalucía, pp. 21-50.

MEMBRADO, J.; HUETE, R. y MANTECÓN, A. (2016): “Urban Sprawl and Northern European Residential Tourism in the Spanish Mediterranean Coast", Via Tourism Review, vol. 10.

MURRAY, I., BLÁZQUEZ, M. y AMER, J. (2010): "Doblers, poder i territori de 'marca balear' (1983-2009)", Journal of Catalan Studies, no 13, pp. 321-350. 
NAREDO, J. (2010): "El modelo inmobiliario español y sus consecuencias", Boletín $C F+S, \mathrm{n}^{\circ} 44$, pp. 13-27.

NAVARRO IBÁÑEZ, M. y BECERRA DOMÍNGUEZ, M. (1992): "El turismo en Canarias 1985-1991", en Geografía de Canarias 1985-1991. Santa Cruz de Tenerife, Editorial Intersinsular Canaria, pp. 156-182.

OBIOL MENERO, E.M. y PITARCH GARRIDO, M.D. (2011): "El litoral turístico valenciano. Intereses y controversias en un territorio tensionado por el residencialismo", Boletín de la Asociación de Geógrafos Españoles, n 56, pp. 177-200.

OCAÑA OCAÑA, M.C. (2009): "Urbanización y vivienda, negocio financiero y conflicto social", en Territorios, sociedades y políticas. Sevilla, Universidad Pablo de Olavide y Asociación de Geógrafos Españoles, pp. 349-368.

PARREÑO CASTELLANO, J. y DÍAZ HERNÁNDEZ, R. (2010: “La ordenación territorial, urbanística y de los espacios naturales protegidos y el modelo territorial en la Comunidad Autónoma de Canarias (1982-2009)", en Cuadernos Geográficos, n 47 , pp. 429-451.

PULIDO FERNÁNDEZ, J.I. (2011): "La sostenibilidad del modelo turístico español en un escenario de cambio global", Papeles de Economía Española, n ${ }^{\circ} 128$, pp. 38-52.

RODRÍGUEZ, E. y LÓPEZ, I. (2011): "Del auge al colapso. El modelo financieroinmobiliario de la economía española (1995-2010)", Revista de Economía Crítica, no 12, pp. 39-63.

ROMERO GONZÁLEZ, J. (2010): “Construcción residencial y gobierno del territorio de España. De la burbuja especulativa a la recesión. Causas y consecuencias", Cuadernos Geográficos, $\mathrm{n}^{\circ}$ 47, pp. 17-46.

ROMERO, J., JIMÉNEZ, F. y VILLORIA, M. (2012): “(Un)sustainable territories: causes of the speculative bubble in Spain (1996-2010) and its territorial, environmental, and sociopolitical consequences", Environment and Planning C: Government and Policy, vol. 30, pp. 467-486.

RUEDA, S. (2002): “Una nueva ordenación del territorio para una sociedad de redes", en Redes, territorios y gobiernos. Nuevas respuestas locales a los retos de la globalización. Barcelona, Diputació de Barcelona, pp. 269-293.

RULLAN SALAMANCA, O. (1999): "La nueva Ley del Suelo de 1998 en el contexto del neoliberalismo postmoderno", Investigaciones Geográficas, n 22 , pp. 5-21.

RULLAN SALAMANCA, O. (2005): "Una técnica urbanística para contener el crecimiento residencial en espacios con fuerte presión inmobiliaria", Scripta Nova. Revista electrónica de geografía y ciencias sociales, vol. IX, nº 194 (32).

RULLÁN SALAMANCA, O. (2008): "Reconversión y crecimiento de las zonas turísticas: del fordismo al postfordismo", en Destinos turísticos: viejos problemas, ¿nuevas soluciones? X Coloquio de Geografía del Turismo, Ocio y Recreación, pp. 587-626.

RULLAN SALAMANCA, O. (2011): "La regulación del crecimiento urbanístico en el litoral mediterráneo español", Ciudad y Territorio. Estudios Territoriales, vol. XLIII, $\mathrm{n}^{\circ} 168$, pp. 279-297.

RULLAN SALAMANCA, O. (2012): “Urbanismo expansivo en el Estado Español: de la utopía a la realidad", en Geografía y desafíos territoriales en el siglo XXI. Alicante, Asociación de Geógrafos Españoles y Universidad de Alicante, pp. 165-209. 
RULLAN SALAMANCA, O. y ARTIGUES, A (2007): "Estrategias para combatir el encarecimiento de la vivienda en España. ¿Construir más o intervenir en el parque existente?", Scripta Nova Revista Electrónica de Geografía y Ciencias Sociales, vol. $\mathrm{XI}, \mathrm{n}^{\circ} 245(28)$.

SANTOS PAVÓN, E. y FERNÁNDEZ TABALES, A. (2010): "El litoral turístico español en la encrucijada: entre la renovación y el continuismo", Cuadernos de Turismo, ${ }^{\circ}$ 25, pp. 185-206.

SIMANCAS CRUZ, M. (2015): La moratoria turística de Canarias. La reconversión de un destino turístico maduro desde la Ordenación del Territorio. San Cristóbal de La Laguna, Servicio de Publicaciones de la Universidad de La Laguna.

SWYNGEDOUW, E., MOULAERT, F. y RODRÍGUEZ, A. (2002): "Neoliberal urbanization in Europe: large-scale urban development projects and the new urban policy", Antipode, $\mathrm{n}^{\circ} 34$, pp. 543-577.

VERA REBOLLO, F. (1990): "El auge de la promoción inmobiliaraia y sus efectos en la reestructuración de la oferta en el litoral alicantino", Treballs de Geografía, n 40, pp. 81-88.

VILLAR ROJAS, F. (2003): "La ordenación territorial del turismo: luces y de la limitación del crecimiento turístico en Canarias", Actualidad Administrativa, n 24, pp. 579-616. 
